\title{
Artemisia scoparia Waldst. \& Kit. and Artemisia annua $L$. in the collection of aromatic and medicinal plants of the Nikitsky Botanical Garden
}

\author{
O.M. Shevchuk ${ }^{1}$, L.A. Logvinenko ${ }^{1}$, T.D. Mezenova $^{2}$, and D.A. Konovalov, ${ }^{2, *}$ \\ ${ }^{1}$ Nikitsky Botanical Garden of Order of the Red Banner of Labor - National Scientific Center of the \\ Russian Academy of Sciences, Nikitsky Descent, 52, 298648 Nikita, Yalta, the Republic of Crimea, \\ Russia \\ ${ }^{2}$ Pyatigorsk Medical and Pharmaceutical Institute - branch of the FSBEI HE VolgSMU of the \\ Ministry of Healthcare of Russia, Kalinina Avenue, 11, 357532 Pyatigorsk, Russia
}

\begin{abstract}
The article presents the results of the study of Artemisia scoparia Waldst. \& Kit. (paniculate wormwood) and Artemisia annua L. (annual wormwood), grown in the Nikitsky Botanical Garden - National Scientific Center of the Russian Academy of Sciences (NBG-NSC RAS). The Nikitsky Botanical Garden is the originator of Artemisia scoparia cv. varieties. Tavrida and Artemisia annua cv. Novichok, which are included in the Register of varieties of Russia allowed for distribution in the south of Russia. Both varieties are of interest as resource varieties having a significant potential for use as sources of essential oil, biologically active compounds, as well as aromatic and medicinal. Analysis of samples of the aboveground part of plants showed that the maximum content of essential oil in Artemisia scoparia accumulates at the end of flowering $(1.78 \pm 0.15 \%$ of the dry weight), and in Artemisia annua - at the beginning of flowering (2.95-3.14\% of the dry weight). In addition, the essential oil of Artemisia scoparia is a valuable source of polyacetylene compounds (capillin, capillene), and the aboveground part of Artemisia annua is a source of artemisinin sesquiterpene lactone.
\end{abstract}

\section{Introduction}

The Nikitsky Botanical Garden - National Scientific Center (NBG-NSC) has been forming its collections since the day of its creation as one of the leading scientific institutions in Russia. Until the present, the collection policy of the Garden is based on maintaining the main generic, species and varietal diversity that has developed over many years of its existence, as well as enriching it with economically promising species. For almost 100 years, the collection of essential oil and medicinal plants has served not only as a base for introduction and breeding research, but also has a utilitarian value. During this period, 49 varieties were obtained, and the gene pool collection includes 342 species.

* Corresponding author: d.a.konovalov@pmedpharm.ru 
Genus Artemisia L. is one of the most represented generic complexes in the collection. The richness of its species diversity allowed to consider many species as valuable essential oil and medicinal crops [1-3]. Many years of experience in the introduction of 48 species of Artemisia L. have shown a variety of their biochemical composition. Thus, for example, essential oils of some wormwood: tauric (Artemisia taurica Willd.), santonic (Artemisia santonica L.), lemon (Artemisia balchanorum Krasch.), paniculate (Artemisia scoparia Walds. et Kit.), absinth (Artemisia absinthium L.,) can serve as a source of geraniol, linalool, citral, eugenol, azulenes (guaiazulene, artemazulene, etc.), capillene, capillin and other valuable components, which determines the prospects for using their raw materials for perfume and cosmetics, food and pharmaceutical industries [4, 5].

Artemisia scoparia Waldst. \& Kit. (paniculate wormwood) and Artemisia annua L. (annual wormwood) are of considerable interest as essential oil, spicy-aromatic and medicinal plants among the annual-biennal species of this genus.

Polyacetylene compounds of Artemisia scoparia essential oil are the main components associated with its phytotoxic, antimicrobial and antifungal properties [6-9].

Essential oil and sesquiterpene lactones are described in the scientific literature as the main biologically active components of the aboveground part of Artemisia annua [10, 11]. A number of the most effective antimalarial drugs have been developed on the basis of sesquiterpene lactone artemisinin, and their anti-cancer activity is being actively investigated [12].

In order to obtain the maximum collection of essential oil (EO) and main active substances from the aboveground mass of Artemisia scoparia cv. 'Tavrida' and Artemisia annua cv. 'Novichok' varieties, the dynamics of their accumulation during the growing season was studied within the framework of a competitive variety testing.

\section{Materials and methods}

The experimental site is located on the Southern coast of the Crimea (SCC) with geographical coordinates $44^{\circ} 31^{\prime} \mathrm{N}, 34^{\circ} 15^{\prime} \mathrm{W}$. The soil is light-clay carbonate with a humus content of $2.96 \%$ [13]. The climate is dry subtropical of the Mediterranean type, with an average annual air temperature of $+13.5 \pm 1.5^{\circ} \mathrm{C}[14]$.

Features of the biological development and morphology of plants Artemisia scoparia cv. 'Tavrida' and Artemisia annua cv. 'Novichok' was studied according to the method of V. P. Isikov, V. D. Rabodyagov, L. A. Khlypenko and co-authors, developed in the Nikitsky Botanical Garden [15].

The quantitative content of essential oil was determined by the method of air-steam distillation, using the Ginsberg device and the Clevenger device [16].

Polyacetylene components of essential oil of Artemisia scoparia cv 'Tavrida' was identified by chromatography in a thin layer of sorbent (TLC) with densitometric registration of the analytical signal. The results of the study were processed using the program "Videodensitometr Sorbfil" (Russia). During the study, plates for TLC "Sorbfil" PTSH-P-A-UV, eluent - hexane-ethyl acetate (9:1) were used. The plates were developed in UV light. The method of quantitative determination of the main polyacetylenes of Artemisia scoparia essential oil was validated for its specificity, sensitivity, linearity, correctness and precision [17]. This technique was used to study the dynamics of accumulation of the main polyacetylene compounds of the aboveground mass of this type of wormwood in order to establish the optimal timing of raw material procurement.

Samples of the aboveground mass of annual wormwood for the quantitative determination of artemisinin were harvested during the mass flowering phase. Air-dry raw materials were ground to the size of particles passing through a sieve with a hole diameter 
of $1 \mathrm{~mm}$. Then it was extracted with chloroform for a day in a ratio of 1:25 at room temperature. After a day, the extractant was distilled, and the dry residue was dissolved in $30 \mathrm{ml}$ of $70 \%$ ethyl alcohol.

Artemisinin, produced in Vietnam, was used as a standard sample (SS). Chromatography was performed using petroleum ether-ethyl acetate (8:2) as an eluting mixture. When the process was completed, the plates were kept in a laboratory hood until the eluent was completely removed. Chromatograms were developed by spraying them with a mixture of ethanol - acetic acid (glacial) - sulfuric acid (conc.) - anisic aldehyde at a component ratio of 17:2:1:0.1, followed by heating at a temperature of $100-110{ }^{\circ} \mathrm{C}$.

A working standard sample (WSS) of the polyacetylene compound capillin and a standard sample (SS) of the sesquiterpene lactone artemisinin were used in studies.

\section{Results and discussion}

In the Nikitsky Botanical Garden, the introduction and selection study of annual and paniculate wormwood was carried out in the direction of obtaining oilseed forms with a valuable chemical composition as promising sources of domestic raw materials. The study of numerous samples of Artemisia scoparia, brought from different places of natural growth (Georgia, Azerbaijan, Krasnodar Krai, the Crimea) and introduced in the conditions of the NBG collection nursery, showed that the studied samples can be divided into 3 groups according to essential oil content:

- with low oil content $(0.20-0.25 \%$ in fresh raw material equivalent);

- with average content $(0.37-0.40 \%$ in fresh and $0.93 \%-0.98 \%$ dried raw material equivalent);

- with high content (more than $0.50 \%$ in fresh and more than $1.0 \%$ dried raw material equivalent).

All subsequent selection, i.e. directed breeding, was carried out on the basis of samples of the third group using multiple individual selection. As a result, the variety Artemisia scoparia cv 'Tavrida' was developed.

Currently, NBG is the originator (creator) of the Artemisia scoparia cv 'Tavrida' and Artemisia annua cv. 'Novichok' varieties, which are included in the list (register) of plant varieties allowed for distribution in the south of Russia.

The paniculate wormwood variety Tavrida is unpretentious to cultivation conditions, grows well in the conditions of culture, withstands drought, salinization, is not damaged by pests and diseases. The most effective method of its propagation is its seed reproduction. When sowing seeds for winter in March (the second or third decade), seedlings appear, and after 2-3 weeks, the leaf rosette is formed. After about a month, the plants of this variety enter the phase of active growth of shoots. Flowering of plants begins in late summer (midAugust - whole September). Seeds ripen in October - early November.

The variety is characterized as high-yielding (68-70 c/ha) and high-oil. The essential oil is light brown in color with a red-brown tint and a pronounced clove-pepper aroma. The density is $0.91-0.97$, the refractive index is $1.50-1.51$.

Variety Artemisia annua L. cv. 'Novichok' is characterized by active seed germination, subsequent intensive growth and development processes at the autumn sowing dates in the conditions of the Southern coast of the Crimea; it is very responsive to the presence of moisture in the soil in early spring. The plant height reaches $220-240 \mathrm{~cm}$. The variety is high-yielding, the collection of raw materials is up to $130 \mathrm{c} /$ ha. Seed germination lasts 1.5 years, after which it is significantly reduced.

Essential oil is a slightly mobile liquid of a slightly yellow color with a characteristic pleasant smell. Its yield from 1 ha is up to $40 \mathrm{~kg}$. The essential oil of this annual wormwood 
variety is characterized by a significant content of artemisia-ketone (50.2-55.1\%) and camphor (up to $15 \%$ ).

The highest content of essential oil is found in the raw material (grass) in the flowering phase (up to $1.15 \%$ in fresh raw material equivalent), then gradually decreases until the seeds mature. Such dynamics of the essential oil accumulation in the aboveground part of the plant allows to consider end of August - beginning of November as the optimal period for raw material preparation. The essential oil yield obtained by different methods (using the Ginsberg device and the Clevenger device) demonstrates that the second method is less effective (up to $0.95 \%$ in terms of fresh raw materials) compared to the Ginsberg method (up to $1.15 \%$ in fresh raw material equivalent). The oil obtained by this method is characterized by a lower mass fraction of the main components - artemisia-ketone and camphor, as well as a significant total content of terpenoids (sesquiterpenes and monoterpenes).

It was found that the formation of the essential oil of Artemisia scoparia cv. 'Tavrida' occurs already at the stage of shoot formation, amounting to $0.43-0.46 \%$ in fresh raw material equivalent. The highest content of essential oil was found in the flowering phase $0.84-0.86 \%$ in fresh and $1.77-1.79 \%$ in dried raw material equivalent. During this period, it is characterized by a high content of target components (capillene, capillin).

Capillin (Rf 0.59-0.62), capillene ( Rf 0.78-0.82) and capillol (Rf 0.27-0.31) were identified as the main components of the essential oil on TLC plates (Fig. 1). Identification was carried out with the help of witnesses (WSS) of capillin, capillene and capillol, previously isolated by us by column chromatography.

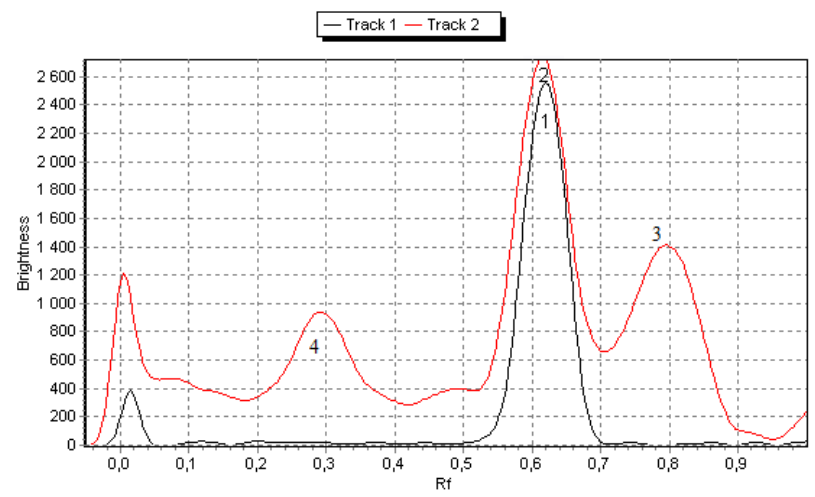

Fig. 1. Digitized chromatogram of polyacetylenes of paniculate wormwood essential oil: capillin (2), capillene (3), capillol (4) and capillin WSS (1)

The use of the internal normalization method allowed to determine the quantitative content of these components in the essential oil during the growth and development of Artemisia scoparia cv. 'Tavrida'.

Table 1. Dynamics of polyacetylene accumulation in the aboveground part of Artemisia scoparia cv.

'Tavrida' depending on development phase

\begin{tabular}{|l|c|c|c|}
\hline \multirow{2}{*}{ Ontogenesis stage } & \multicolumn{3}{|c|}{ Content in essential oil (in \%)* } \\
\cline { 2 - 4 } & capillin & capillene & capillol \\
\hline Branching & $\mathbf{4 6 . 1 - 4 8 . 5}$ & $25.4-26.8$ & $\mathbf{1 9 . 8 - 2 1 . 2}$ \\
\hline Budding & $8.7-10.4$ & $60.2-62.5$ & $14.7-15.8$ \\
\hline Flowering & $6.4-7.9$ & $\mathbf{6 3 . 1 - 6 6 . 7}$ & $2.1-2.9$ \\
\hline Seed maturation (fruiting) & $1.2-1.8$ & $11.3-13.1$ & $<0.1$ \\
\hline
\end{tabular}

* - these tables reflect the average values of the results obtained in the period 2018-2020. 
As it follows from the data presented in Table 1, reflecting the results of three-year observations, the capillin content reaches a maximum in the branching phase, and as Artemisia scoparia cv. 'Tavrida' develops it is declining. The capillene content, on the contrary, gradually increases from $25.4-26.8 \%$ (in the branching phase) to $63.1-66.7 \%$ (in the mass flowering phase). The capillol content in the aboveground part of this object does not exceed $21.2 \%$ during the branching phase and gradually decreases with plant development, reaching a minimum during the fruiting period.

The annual wormwood variety Novichok is an annual plant with a height of $2.0-2.3 \mathrm{~m}$. The most effective method of reproduction of this species is seed, as in the case of paniculate wormwood. When sowing seeds for winter, the active formation of plants occurs until the second decade of August and lasts 1-1.5 months. The seeds ripen in SeptemberOctober. The yield of the aboveground mass is more than $90 \mathrm{c} / \mathrm{ha}$, which allows to classify this variety as high yielding.

The main components of the essential oil are artemisia-ketone (more than 50\%) and camphor (up to $15 \%$ ) [4]. In appearance, the oil is a more or less mobile slightly yellowish liquid with a characteristic taste. Maximum accumulation of volatile oil in the aboveground part of Artemisia annua cv. 'Novichok' occurs in the flowering phase - up to $1.2 \%$ in fresh and more than $3 \%$ in absolutely dry raw material equivalent (Fig. 2).

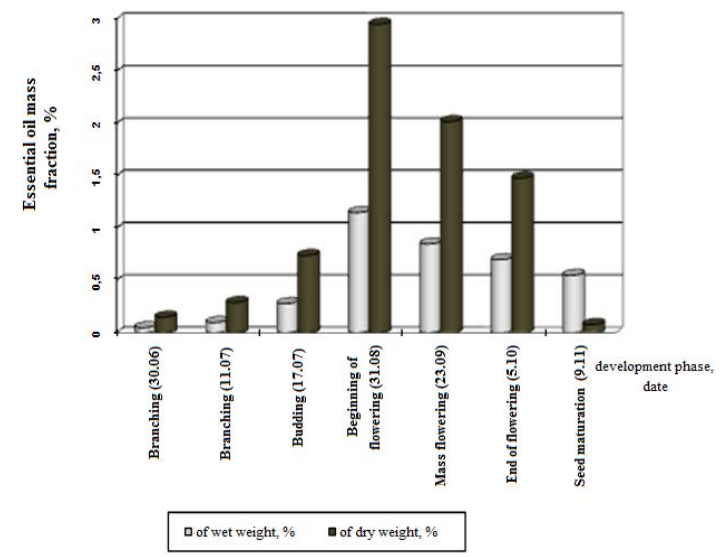

Fig. 2. Dynamics of essential oil accumulation in raw material of Artemisia annua cv. 'Novichok'

Figure 3 shows a digitized chromatogram of chloroform extraction (after removing the solvent and dissolving the residue in $70 \%$ ethyl alcohol) from the aboveground mass of Artemisia annua cv. 'Novichok'.

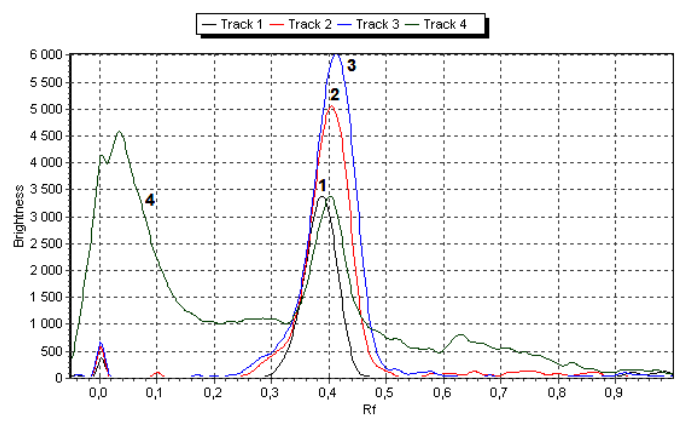

Fig 3. Digitized chromatogram of chloroform extraction (4) and artemisinin SS (1 - $3 \mu \mathrm{g} / \mu \mathrm{l} ; 2$ - 4 $\mu \mathrm{g} / \mu \mathrm{l} ; 3-5 \mu \mathrm{g} / \mu \mathrm{l})$. 
Table 2. Artemisinin content in the aboveground mass of Artemisia annua cv. 'Novichok' by development phase

\begin{tabular}{|c|c|}
\hline Ontogenesis stage & Content, $\mathbf{g} / \mathbf{1 0 0} \mathbf{g}$ of raw materials \\
\hline Branching & $0.10 \pm 0.02^{*}$ \\
\hline Budding & $0.13 \pm 0.02$ \\
\hline Flowering & $\mathbf{0 . 2 6} \pm \mathbf{0 . 0 5}$ \\
\hline Fruiting & $0.15 \pm 0.02$ \\
\hline Seed maturation & $0.11 \pm 0.03$ \\
\hline
\end{tabular}

* - these tables reflect the average values of the results obtained in 2020.

The results presented in Table 2 show that the highest content of artemisinin in the aboveground mass of Artemisia annua is found during the flowering phase. This is probably the optimal period for raw material harvesting.

The results of the conducted studies, as well as previously published studies $[6,7]$ and literature data [8-11] show that the aboveground parts of the varieties Artemisia scoparia cv. 'Tavrida' and Artemisia annua cv. 'Novichok', grown in the Nikitsky Botanical Garden, are a valuable source of essential oils and other biologically active compounds (polyacetylenes and artemisinin sesquiterpene lactone).

The TLC method used in this work with densitometric registration of the analytical signal allows to reliably control the content of the target components in the raw material with sufficient accuracy and can be recommended for subsequent use in order to assess the quality of the studied raw materials.

\section{Conclusions}

1. As a source of essential oil with the highest content of target components (artemisia-ketone (more than 50\%), camphor (up to 15\%) and sesquiterpene lactone artemisinin), the aboveground part of Artemisia annua cv. 'Novichok' collected in the flowering phase is of interest, with an essential oil content of up to $1.2 \%$ in fresh and more than $3 \%$ in absolutely dry raw material equivalent.

2. The aboveground part of the variety Artemisia scoparia cv. 'Tavrida' collected in the flowering phase contains $0.84-0.86 \%$ of essential oil in fresh and $1.77-1.79 \%$ in dried raw material equivalent. During this period, it is characterized by a high content of target components (capillene, capillin).

\section{References}

1. L.A. Logvinenko, O.M. Shevchuk, Zemledeliye, 7, 16 (2020)

2. M. Ranjbar, M.R. Naghavi, H. Alizadeh, Journal of Essential Oil Research, 32(4), 361 (2020)

3. S. Kordali, R. Kotan, A. Mavi, et al., Journal of Agricultural and Food Chemistry, 53(24), 9452 (2005)

4. L.A. Logvinenko, O.M. Shevchuk, Proceedings of the Kuban State Agrarian University, 5(68), 96 (2017)

5. L.A. Logvinenko, O.M. Shevchuk, E.N. Kravchenko, Agrarian Bulletin of the Urals, 4(183), 59 (2019)

6. D.A. Konovalov, O.A. Konovalova, V.A. Chelombit'ko, Chemistry of Natural Compounds, 28(1), 121 (1992) 
7. D.A. Konovalov, V.A. Chelombit'ko, Plant Resources (USSR), 27, 135 (1991)

8. D.A. Konovalov, Pharmacy \& Pharmacology, 4(5), 23 (2014)

9. D.A. Konovalov, Plant Resources, 32(4), 84 (1996)

10. D.A. Konovalov, A.A. Khamilonov, Pharmacy \& Pharmacology, 4(4), 4 (2016)

11. D.A. Konovalov, O.M. Shevchuk, L.A. Logvinenko, A.A. Khamilonov, Pharmacy \& Pharmacology, 4(5), 4 (2016)

12. D.A. Konovalov, A.A. Khamilonov, O.M. Shevchuk, L.A. Logvinenko, Pharmacy \& Pharmacology, 6(5), 402 (2018)

13. T.I. Orel, Simferopol: IT "Arial", 72 (2018)

14. Yu.V. Plugatar, S.P. Korsakova, O.A. Ilnitsky, Simferopol: IT "ARIAL", 164 (2015)

15. V.P. Isikov, V.D. Rabotyagov, L. A. Khlyoenko et al, Introduction and breeding of aromatic and medicinal crops. Methodological and instructional aspects, 110 (2009)

16. GOST 34213-2017. Interstate standard. Essential oil floral and herbaceous raw material. FSUE "Standartinform", www.gostinfo.ru

17. E.E. Ayrapetyan, T.D. Mezenova, O.M. Shevchuk, L.A. Logvinenko, D.A. Konovalov, Bulletin of the Volgograd State Medical University, 1(73), 173 (2020) 